\title{
Appendicitis in the Elderly
}

\author{
Stephen Garba and Adamu Ahmed \\ Ahmadu Bello University, Zaria, \\ Nigeria
}

\section{Introduction}

Appendicitis in the elderly is a pathological process. It is common in many locales, populations and cultures. It is a potentially life threatening pathology. Lifetime incidence is 1 in every 15 persons $(7 \%)$ with a prevalence rate of ten in one hundred thousand people $(10 / 100,000)$ (Condon RE, 1986). Appendicitis usually affects people who are previously healthy. The rate of appendicitis among the elderly varies from $5 \%$ to $10 \%$ of appendicitis cases. Appendicitis is often thought of as a disease of the young but it has now become a disease of the elderly because of increasing life expectancy of the modern day man resulting from improved medical attention. It is the most common cause of acute surgical condition of the abdomen (Hardin D, 1999, Storm-Dickerson T.L. \& Horattas, M.C., 2003). Appendicitis requires immediate surgical excision in most cases as soon as the condition is diagnosed unless contraindicated. If appendicectomy is carried out early, the end result is low morbidity and mortality. The cure rate is high if managed early without any long term sequelae (Birnbaum BA \& Wilson SR, 2000; Ellis H, 1989). This write up will focus on appendicitis in the elderly. The elderly as defined in this discussion are people who are sixty years of age and above. The high occurrence of appendicitis has made the pathology a very important entity that should not be under estimated. The usual peak incidence of appendicitis in the general population is in the range 15 to 24 years age group. This accounts for $5 \%$ of all acute abdominal conditions in the aged 65years and above (Sheu, B F. et al, 2007; Storm-Dickerson T.L. \& Horattas M.C., 2003).

The elderly patients have a lowered physiological reserve. Inflammatory effect is much increased in the elderly. Hence appendicitis has a more fulminant outcome in this group of patients. The mortality can be as high as 16 times as what is obtainable in the young adult with appendicitis (Hui TT, et al, 2002; Semm K, 1983). There has been increased use of computed tomography $(\mathrm{CT})$ in the last two decades. This investigative tool has improved the diagnosis of appendicitis (Horattas M, 1990). In the area of care, laparoscopy has revolutionized the care of appendicitis since the introduction of the first laparoscopy appendicectomy performed in 1983 by Semm (Tehrani H, 1999). A high rate of misdiagnosis of appendicitis in the elderly has been documented (Hale D, 1997). This is because this disease simulates much other pathology in the elderly. The elderly people have deteriorating functions of their organs system which in that state may mimic the pathology of appendicitis. Some of these pathologies shall be discussed latter in this write up. The presentation of appendicitis can be traditional or non classical. There is high rate of atypical or non classical presentation among the elderly patients than in the general setting. In contrast to this, the majority of young adults present classically. This atypical presentation in the elderly patients leads to delay diagnosis with resulting high 
complications among them. This peculiarity has made many to say appendicitis in the elderly is a separate entity (Carr NJ, 2000; Blomqvist P, 2001).

The young adult with appendicitis presents mainly with classical features and this made it easy to make correct diagnosis, early and appropriate treatments can then be easily instituted. The elderly presents with a higher degree of non classical features, has delay attention because of delay correct diagnosis. In general the non classical features made diagnosis difficult hence higher morbidity and mortality. Appendicitis has a perforation rate of $17-20 \%$ in general. Bear in mind that in the elderly however, appendicitis appearance is usually not apparent, presenting as if it is not present. Hence delay in diagnosis and treatment is common with poorer outcome. There is need for expedient diagnosis of appendicitis in the elderly today. This is because the elderly proportion in the society has increased due to improved medical attention (Lee JF, 2000). Better Medicare has resulted in increased proportion of the elderly in the population. Physicians must always have in mind that appendicitis is a regular pathology in the elderly with irregular presentations. A high index of suspicion is a good practice principle. Every physician must familiarize himself with appendicitis unusual presentations. Apart from the elderly patients, other group of patients with a high degree of non classical presentations include the children, the pregnant and the acquired immune deficiency syndrome (AIDS) patients (Krisher S, 2001). They all have peculiar pathologic appendices.

Treatment outcome for young adult and the elderly with appendicitis are similar if correct diagnosis is made and patients are treated promptly. That is to say the result of treatment of appendicitis in the elderly can be as excellent as in the young adult (Rao P, et al 1999; Schumpelick V, et al 2000). Despite the profound improvements in the diagnosis and treatments of appendicitis in general and in the elderly in particular, the morbidity and mortality is still high (Gupta H \& Dupuy D, 1997; Temple C, et al, 1995, Yamini D, 1998). Some have even reported a perforation rate as high as $70 \%$ at presentation because of this peculiar problem (Paranjape, et al 2007). Can we then say appendicitis is a separate entity in the elderly? There is no doubt that the outcome in this group of patients is poorer because of delay diagnosis and delay treatment all on the account of non-classical mode of presentation. Very few young adult patients present with 'out of character' manifestations of appendicitis (Nguyen D, et al 1999). When Reginald Fitz first described the condition of appendicitis in 1886, the mortality from acute appendicitis was $40 \%$.( Lin CJ, et al, 2005). Now with the introduction of general anaesthesia, antiseptic techniques and the availability of powerful antibiotics, the reported mortality rate has dropped significantly. However these improved medical practices have not completely eradicated the issue of delay diagnosis and late administration of appropriate treatments (Hardin D, 1999). This chapter will further address the characteristics of appendicitis in the elderly and where necessary compares it with appendicitis in the young adults. It will discuss the factors that are contributory to its high morbidity and mortality and how to regulate these morbidity and mortality modifiers of appendicitis in this category of patients. The modern imaging systems that are helpful in speedy diagnosis shall be highlighted in this discussion. Treatments and ways to improve the treatments shall be fully discussed with special regards to the elderly.

\section{Pathology}

This discussion on the pathogenesis of appendicitis will center more on the classical form of obstructing lesion leading to appendicitis. Only where necessary will the non obstructive 
form of appendicitis be mentioned. This vestigial organ can be involved in inflammation like other organs of the body. There are many factors that may lead to its inflammation but in general the inflammation starts in the mucosa and progresses into the deeper tissues of the appendix wall (Yamini D, et al, 1998). In no doubt there are many factors exacerbating the process of appendicitis in the elderly. These factors may be anatomic or physiologic in origin. What are the anatomical and physiological changes that enhance a different inflammatory response of appendix to inflammation in the elderly as compared to the young adults? The inflammatory process occuring in appendix following some initiators is greatly modified by many factors in this group of patients. Most of these factors are due to anatomical and physiological changes in the elderly. It is therefore very important for all attending physicians to know the peculiarity of inflammatory changes affecting the appendix in the elderly. It is this peculiarity that makes more of the appendicitis in the elderly to present atypically hence has worse prognosis as compared to the young adults with similar pathology (Hardin D, 1999; Yamini D, et al, 1998).

\subsection{Anatomy}

This section describes the changes in the appendix with age that make it respond to inflammations differently from the young adults. With aging the serosa of appendix becomes relatively less elastic compare to the elasticity quality of the mucosa of the appendix. In the young the elasticity of both is good and comparable. Because of significant differences in the elasticity of the serosa and the submucosa, the response to intraluminal pressure is different. The adaptation of them to stretch from luminal accumulation of secretions is different leading to relative ischaemia and early gangrene of the wall of appendix. This is a great factor in the pathogenesis of early perforation of appendicitis in the elderly. There is however other anatomical changes that enhances worse inflammatory response in the pathogenesis of appendicitis in the elderly which are associated with aging. Another important factor is that with age, the blood supply to the appendix is affected by atherosclerosis. It reduces the pliability of arterial and venous supply to the appendix. The wall of the appendix is weakened by fibrosis and fatty infiltration. There is progressive atrophy of lymphoid tissue with concomitant fibrosis of the wall of the appendix. This causes partial or total obliteration of the lumen. One of the overall effects is narrowed or occluded appendix. These make appendix more prone to ischaemia in any problem that involves a reduction of blood flow to the appendix as found in luminal blockade. The elderly has weakened peristalsis. This weakened peristalsis encourages food residue to form in the appendix. The food residue forms bezoar allowing secretions to accumulate in the appendix lumen (Maxwell JM \& Ragland JJ, 1991). At old age the openings of appendix will atrophy which aids regurgitation of stool, undigested food, parasites, making it easy to enter the appendix lumen causing obstruction, local tissue ischaemia and necrosis of the appendix (Peltokallio P \& Jauhianinen K, 1970). The weakened wall of appendix also encourages the accumulations of these materials. Appendix in the elderly therefore has tendency for secretions to accumulate and prone to ischaemia on the platform of anatomic changes enumerated above.

\subsection{Physiologic changes}

Physiologically, the elderly patients with deteriorating organs have lower physiological reserve than the young adults. They also have higher pain threshold response. They have poor reflexes in general and poor localisation of pain. The initial symptoms in the elderly 
patients with appendicitis are usually attributed to indigestion or constipation, thus ignoring the initial symptoms until they worsened. These declining physiologic functions exacerbate morbidity and mortality in the elderly. Another important factor contributing to increased pathological changes in the appendix is reduced local immunity in the appendix. There is poor inflammatory response from inflammatory cells. All these will also cause decrease ability to eliminate bacteria invasion hence faster bacterial multiplication without much interference. Local tissue factor in bacterial control is poor. The overall effects of these changes in the anatomy and the physiology of appendix is narrowing of the appendix lumen, decreased local tissue defence capability, and loss of mucosal integrity paving way for bacterial invasion of appendix (Horattas MC \& Haught R, 1992). Bacterial invasion leads to rapid pus formation and gangrene with perforation and generalised inflammation of the peritoneum.

\subsection{Aetiology}

The process of inflammation in appendix starts most times from the mucosa with luminal obstruction of the appendix. As in other forms of intestinal obstruction, the obstructing lesion may be extrinsic, intramural or intraluminal. Appendix inflammation can however occur without any form of obstruction. In appendicitis, obstruction is more commonly of intraluminal variety than other forms of initiators. Obstructive appendicitis is commoner than catarrhal appendicitis even among the elderly. In catarrhal appendicitis, inflammation occurs without any form of obstruction. In cases of obstructive appendicitis, obstruction is usually due to matters such as faecolith which starts the process of inflammation from the mucosa of the appendix. The opening of appendix into the large bowel is prone to blockade from the content of the large intestine hence encouraging stasis in the lumen of the appendix. Inflammation resulting from non obstructive changes in the mucosa of the appendix is purely bacterial in origin (Carr NJ, 2000; Maxwell JM \& Ragland JJ, 1991). The other obstructive lesions are response to a generalized lymphoid tissue from systemic infectious diseases by bacterial enterocolitis or by fecalith from foreign body or blockade from intestinal parasites. The bacterial that are usually involved in the inflammation are usually coliform organisms. Most of the obstructions are followed by infection with streptococcus pneumoniae.

\subsection{Pathogenesis}

In the majority of cases, the initiating factors of obstruction above leads to luminal stasis and obstruction causing impediments to the flow of the content of appendix. The obstruction distends the wall starting from the mucosa. As stated earlier there is relative unequal elasticity of the mucosa and the submucosal area of the appendix. Therefore there is unequal stretch effect on the mucosal distinct from that of submucosal area leading to early necrosis of the mucosa. A continued secretion within the lumen further increases the pressure in the lumen of the appendix (Lee, J. F. Y., et al 2000). This leads to an initial stage of lymphatic obstruction being the first culprit. This initial impairment of the lymphatic system causes edema, diapedesis of bacteria and mucosa ulceration. Bacterial begins to multiply and there is impairment of integrity of the wall of the appendix. These will therefore cause migration of cells of inflammation through the walls of blood capillaries into the tissue spaces. This leads to organ infection. Mucus further accumulates within the lumen of the appendix. The intraluminal pressure increases steadily as accumulation increases in volume within the appendix (Gupta H \& Dupuy D, 1997; Temple C, et al, 1995). The rapidly proliferating 
intraluminal bacteria convert the accumulated mucus within the appendix into pus. This is an important reaction of appendix to insult of obstruction and infection. This proximal obstruction of the lumen of the appendix by fibrosis or otherwise has long been considered to be the major cause of appendicitis.

If the obstruction is not relieved, there is a further rise in luminal pressure from additional luminal secretion which causes venous obstruction subsequent to the initial lymphatic obstruction. The additional venous obstruction increases the edema, and cause further ischemia of the appendix. The end result of all these changes is suppurative appendicitis (Freund HR, Rubinstein E, 1984). The progression of this pathologic process results in lymphatic, venous and arterial thromboses in the wall of the appendix. As the pressure increases without a relive, the arterial component of the appendiceal vascular supply is jeopardized. A patch or a total gangrenous appendicitis may result from the ischaemia. The final stage in the progression of acute appendicitis is perforation through a gangrenous infarct and spilling of accumulated pus into the peritoneal cavity. This spillage will lead to a localized or generalized peritonitis depending on how fast the body can wall off the offending agents and the degree of perforation. Throughout the stages of inflammation, the body tries to cope with the pathological process with attempts to overcome the insult. The body can fight the offending agent and there can be a complete resolution of the inflammation. However these coping strategies may result in partial restriction of the inflammation leading to formation of appendiceal mass or appendiceal abscess formation (Paajanen H, et al 1994; chapter 83). The classical end result of this inflammation follows a natural course in which there may be a complete resolution of the inflammation, healing with fibrosis, chronic inflammation and/or abscess formation. The common result is however a form of complete resolution, formation of appendiceal mass, development of abscess formation and peritonitis which may be localized or generalized.

An increase in intraluminal pressure in the area distal to the obstruction from increased mucus secretion is followed by an increase in bacteria and, finally, the formation of frank pus. The appendix becomes swollen and the appendiceal wall becomes edematous from obstruction of lymphatic and venous drainage. Ulceration of the mucosa allows invasion of the wall by bacteria. Further progression causes venous thrombosis and obstruction of blood flow through the appendiceal artery. Because this is an end-artery, no collateral circulation is available to prevent ischemic necrosis and gangrene with eventual rupture of the wall. Escape of bacteria through the perforation causes peritonitis. Unless necrosis of the base of the appendix occurs, continued fecal contamination of the peritoneal cavity is prevented by the initial blockage of the appendiceal lumen. The infection in the right lower quadrant can be walled off efficiently in young, healthy patients. In females, this abscess usually involves the right adnexal organs to some extent. The end result is how well the body is able to cope with the inflammatory insult. In appendiceal mass, the inflammatory mass is composed of the inflamed appendix at the core, surrounded with the caecum, the terminal part of the ileum and omentum wrapped all together (Maxwell JM \& Ragland JJ, 1991). The course of the appendiceal mass also may be in the form a complete resolution with the involved organs freed or it may take the form of abscess formation. In appendiceal abscess formation, the previous mass becomes softer, increase in size and patient also will have swing temperature

Generalized peritonitis may ensue in advanced age or in the presence of reduced host resistance from other illnesses or immunosuppression. Perforation is more likely with retrocaecal appendix unnoticed. This is so because in the retrocaecal position, the diagnosis 
of appendicitis is difficult. The difficult diagnosis causes delay in presentation and in the treatment of the pathology hence a high possibility of perforation among the patients (Maxwell JM \& Ragland JJ, 1991). Even with a mild increase in luminal pressure during the early phase of appendicitis, these anatomical and physiological changes may enhance the appendix to early perforation. These changes are exaggerated in the elderly because of the anatomic and physiologic peculiarity. The elderly are not sensitive to pain, symptoms are not typical and therefore there is a rapid progression to perforation without patients' awareness of an ominous disease (Barcia JJ \& Reissenweber N, 2002). Perforation with peritonitis in the elderly appendix is a serious complication. The anatomical and physiological changes rapidly boost perforation of appendix. In the general population, perforation rates range from 20 to $30 \%$, but increase to $50-70 \%$ in the elderly. When is appendicitis considered perforated? The appendix is considered perforated if there is free rupture of intraluminal contents (Fitz HR, 1886). The rupture leads to spillage of intestinal juice into the peritoneum. The peritoneum becomes inflamed as a result of the bacterial contamination of the peritoneal cavity. The characteristics of perforation of appendix in the elderly are suggested by a very sick patient with fever, left shift leucocyte count (increased WBC) and anorexia in addition to abdominal pain. when these features are present, suspect perforation of appendix.

\subsection{Microbiology}

Talking about the biology of the microorganisms involved in inflammatory appendicitis; the flora of the lumen of the appendix is that of the flora of the lumen of the colon. There is a mixture of aerobic and anaerobic organisms involved in appendicitis (Vorhes CE, 1987). The various organisms involved in the inflammatory conditions of appendicitis include anaerobes and aerobes. The common organisms include Escherichia coli, KlebsiellaEnterobacter, Enterococcus faecalis group, Streptococci Clostridia. Fungal infection has also been documented. Any of these organisms can be found in the culture of appendiceal abscess. In an article published by Bernard and Owen in 1978 the organisms cultured in cases of appendicitis include the following: E. coli in $68 \%$ of the patients, the remaining $32 \%$ included organisms such as B fragilis, streptococci, Staph aureus and Klebsiella. In more than $60 \%$ of the cases they were monomicrobial and the remaining polymicrobial (Bernard and Owen, 1978). They were all sensitive to various antibiotics. There is poor response to inflammation from invasion of pathogenic microorganisms and the elderly mount inappropriate response to fever. The total white cell counts are not proportionally increased in inflammation of appendix in the elderly (Barcia JJ \& Reissenweber N, 2002). These peculiarities lead to rapid progression of inflammation, early perforation, and abscess formation in the elderly. Those who develop perforations among the elderly patients with appendicitis usually have higher morbidity and mortality. They are very sick and present more with high and swinging fever, left shift leucocyte count and anorexia.

\subsection{Implications of anatomical and physiological changes}

Is the inflammatory process the same as in the young adults with appendicitis? No, the delay in seeking medical attention and delay in making diagnosis make this inflammatory process in the elderly more serious than in other categories of patients. The anatomical and physiological changes that are noted in the elderly also contribute to a more aggressive inflammatory change in the elderly appendicitis. The outcome of treatments in them is critical because of this delay in presenting to the hospital and also on the account of a more 
aggressive inflammatory response (Lau WY, et al, 1985). There are serious implications for changes in the anatomy and physiology of the appendix of the elderly patients. The consequences of these changes are a different inflammatory response in appendicitis. This different response causes delay and misdiagnosis of this entity in the elderly patient presenting with appendicitis. These changes are the causes of high incidence of atypical presentation in the adult. It can lead to a faster progression of the disease with early perforation of appendix (Smithy WB, 1986). In essence the hardened blood vessels, degradations of appendix, reduced local lymph nodes, poor ability to eliminate inflammation; all encourage aggressive inflammatory response in the elderly appendicitis. Appendix easily perforates and cause localised or diffused peritonitis. Awareness of possibility of appendicitis in the elderly is the master key to successful management of this pathology in the aged people. This group of patients have poor response, their symptoms and pathological changes are often inconsistent with the chief complaint of abdominal pain. The chief symptom in appendicitis is lower abdominal pain and this is most often less severe. Sometimes abdominal pain is not typical, only abdominal distension, nausea and other symptoms are noted. These inconsistent symptoms resulting from differences in the anatomic and physiologic changes are responsible for a high rate of non classical presentation of appendicitis in the elderly. One must bear in mind that many other pathologies mimic appendicitis of this age group. The differential diagnoses therefore are wide and difficult due to their atypical presentations and their aging state. One must consider appendicitis in every elderly patient with lower abdominal pain. This is important because appendicitis takes a more rapid and virulent course in the elderly with weaning organs if treatment is delayed (Horattas MC, et la 1990). On the basis of the pathologic process the following types of appendicitis can be noted: simple, complicated, acute, recurrent and chronic appendicitis.

\section{Clinical features}

The features of appendicitis in the elderly are similar to what is obtainable in the young adults though its presentation is more varied and subtle. Appendicitis can present classically (typically) or nonclassically (atypically). The cardinal symptoms of appendicitis are usually classical and it occurs also in elderly appendicitis (Burns RP, et al 1985). One of the classical symptoms of appendicitis as reported by Burns et al is right lower abdominal pain. In classical cases the pain of appendicitis follows a known classical course. The pain usually starts with sudden periumbilical pain, which becomes localised in the right iliac fossa. Typically the pain is initially diffused, central and minimally severe presenting as visceral pain. In a period of about six to eight hours after the onset of the pain, the pain migrates to the right lower quadrant of the abdomen. This time around the pain is somatic, more severe and usually localized. This is described as visceral - somatic sequence of presentation of pain of appendicitis, This visceral- somatic sequence occur less in the elderly appendicitis as compared to other categories of patients. Atypical form of presentation is common among the elderly patients. Many elderly patients with pain of appendicitis have out of character type of pain. This non classical type of pain stem from the anatomical and physiological changes in the elderly and the anatomic variations in the location of the appendix. These age related and non age related changes account for the non classical sequence of the pain. In the elderly patient with the pain of appendicitis, the pain may be localised in the right lower quadrant from the beginning. This pain also in some patients may be diffused and may never become localized 
(Paajanen H, et al 1994). An elderly patient with retrocecal appendix may have diffuse pain only in the right flank of the abdomen. If the appendix is wholly in the pelvis, there may not be any manifestation of somatic pain but patient may present with tenesmus and lower abdominal discomfort. It is difficult to give a dogmatic sequence of pain presentation in the appendicitis of the elderly. High index of suspicion is needed in every elderly patient with abdominal pain. Every physician must be aware of these forms of pain presentations in appendicitis of the elderly. The next common symptoms after lower abdominal pain are anorexia and nausea. They are present in all cases of appendicitis. Vomiting is present in some cases but not as constant as pain and nausea. Vomiting comes only after the onset of pain and usually once or twice in most cases. If vomiting is persistent, the diagnosis of simple appendicitis should be questioned (Carr NJ, 2000).

Other patients may just have symptoms of irritation of the nearby organs from inflamed appendix. Depending on the location of appendix, if the bladder is being irritate in pelvic appendix, patient may only present with frequent urination and in some cases with haematuria. In some other cases it may be loose stool as a result of irritated bowel. When vomiting is present and profuse it may indicate generalized peritonitis associated with perforation or the diagnosis of appendicitis may be wrong. There is what is called Murphy description of features of appendicitis. The classical presentation as described by Murphy is present in only $50 \%$ of patients of appendicitis. This description starts with colicky central abdominal pain, progressing to pain intensification within 24hours. Pain becomes constant and sharp with loss of appetite, nausea, vomiting and constipation in the elderly. Atypical presentation is usually common with anatomic variations in location of appendix. There will be pain in the right loin in retrocecal appendix, suprapubic pain with urinary frequency or diarrhoea in subcaecal appendix. Remember that left sided appendix occur in $0.25 \%$ of the population resulting from situs inversus or intestinal malrotation. Elderly patients with appendicitis may present only with confusion. From this discussion, it is obvious that appendicitis takes many forms of presentations. In any abdominal pain in the elderly, consider appendicitis.

Anaemia is a common finding associated with appendicitis in the elderly. Patient may be dehydrated, pale, febrile and with foetor oris. Swinging temperature may be noted especially if there is appendiceal abscess from perforation of appendicitis. On further examination of the patients, they may present with other classical signs of appendicitis which include localised tenderness, muscle guarding, and rebound tenderness. There is usually an area of maximal tenderness in the McBurney point (Langenscheidt $\mathrm{P}$, et al 1999). The most important sign is tenderness or rebound tenderness over McBurney point where the bases of majority of all appendixes are located. Charles McBurney (1845-1914) was an American surgeon who, in 1889, described the classic location of sharp pain on a spot exactly between an inch and a half and two inches from the anterior superior process of the ilium on a straight line drawn from the bony prominence to the umbilicus. It is interesting to remember the positions of other parts of the appendix may vary but the bases are constant. Whether the appendix is located in the pelvis, retroileal or in other positions, the point of maximum tenderness of the base is in the McBurney's point. In cases where the appendix is located in the retrocaecal region, tenderness may cover a large area diffusely. Because of the changes in the anatomy and physiological alterations in the aged, these classic signs may be absent. One may be able to elicit the presence of Psoas and obturator signs in these patients. Furred tongue and some levels of dehydration may be noticeable. A rectal examination may reveal right sided pelvic tenderness on rectal examination. 
Basically there are two categories of patients when it comes to presentations of appendicitis in the elderly. There are patients with simple (uncomplicated) appendicitis and patients with complicated appendicitis. Therefore the presentation of patients with perforated appendicitis is quite different from uncomplicated cases in the elderly. Presentation therefore varies depending on the type of appendicitis one is dealing with. For these reasons, the diagnosis of acute appendicitis in the elderly bears many pitfalls due to a broad range of differential diagnoses and uncommon clinical presentation that one may confuse this pathology with. The elderly patients have deteriorating organs, at this age symptoms of which may also imitate appendicitis. Other examination findings include tachycardia, skin flushing, dry mouth, abdominal tenderness, with rebound tenderness and point of maximum tenderness at McBurney point which clinically is at two third along a line from umbilicus to anterior superior iliac spine. There may be muscular rigidity, pain in the right iliac fossa which is intensified with coughing. The pain is usually worse on movement. Patient who presents with atypical features may come with no evidence of muscular rigidity but with tenderness on deep palpation if the appendix is retrocaecal. In subcaecal or pelvic appendix Psoas stretch sign may be present. There may be positive $k$ sign which is tenderness on posterior abdominal wall in patients with retrocaecal or paracolic appendicitis. We must always remember that there are signs we can elicit to exacerbate or localise appendix pain. These signs include Rovsing sign, obturator sign, and psoas sign. In complicated appendicitis where for example there is perforation of appendix and spillage of the content, the physical findings change. Additional findings depend on the nature of the complications the patient had developed. If the infection is contained, the patient often develops a soft, tender mass in the right lower quadrant, and the area of tenderness now encompasses the entire right lower quadrant.

A point for practice is that when patients develop perforated or gangrenous appendicitis with peritonitis, the fever may be high grade and the fever may be swinging. Note that patients with perforation have high temperature as high as $38.3^{\circ}$. There is slight elevation of temperature $(37.80 \mathrm{oc})$ in patient with no perforation. Perforated cases have pronounced left shift leucocyte count and anorexia. People with early appendicitis do not look very ill most times except complicated. Remember the elderly mount poor response to inflammatory changes so in some cases there may not be fever. Absent fever is not an indication that the patient has no appendicitis. The factors that have been found to increase the chance of perforation include: increased age, male sex, presence of fever or anorexia, retrocaecal anatomical position of appendix, peritoneal signs, left-shift leucocytes, a higher C-reactive protein level, and delay in presentation and surgical intervention (Carr NJ, 2000). When these factors are present, possibility of perforation is very high. Several studies have shown that elderly patients have a tendency to present late after the initial onset of symptoms (Barcia JJ \& Reissenweber N). Many authors believe that the delay in presentation is multifactorial. Some of these elderly patients live alone and have difficulty in accessing medical care early while others, with a higher pain threshold, would attribute the symptoms to indigestion or constipation, thus ignoring the initial symptoms until they worsened (Carr NJ, 2000). Another major factor in the delay presentation is the morbid fear of hospitalization among our elderly patients because they equate hospital admission with certain death. Symptoms and pathological changes are often inconsistent with the chief complaint of abdominal pain and less severe (Smithy WB, et al, 1986). Hence patients and attending physician do not take these patients serious until complications develop. Although elevated leukocyte count and CRP value cannot effectively establish the diagnosis of acute appendicitis in the elderly, unelevated 
values exclude it. Accordingly, appendectomy is not recommended to be performed in an elderly patient with unelevated leukocyte count and CRP value, even though clinical symptoms and signs indicate acute appendicitis (Horattas MC, et al, 1990). Awareness is the watch word in elderly appendicitis as several studies have shown that elderly patients have a tendency to present late after the initial onset of symptoms (Carr NJ, 2000; Franz MG, et al, 1995; Smithy WB, et al, 1986). Again, remember to consider appendicitis in all cases of abdominal pains in the elderly.

\section{Diagnosis}

Making the diagnosis of appendicitis is largely clinical and it is based on history, physical examination, and imaging studies. Appendicitis in the elderly has inconsistent manifestations. There are high percentages of patients with atypical presentations in the elderly. Appendicitis is less common in the elderly than in the young, but symptoms are more likely to be ignored by the elderly patient, and the mortality is higher in this aged group, up to $10 \%$. Similarly appendicitis in the elderly often has a delay in diagnosis owing to often vague symptoms, blunted tenderness, and diminished leukocytic responses. Thus, a higher index of suspicion is again required. Diagnosis is difficult as many of the symptoms mimic those associated with aging. Atypical appendicitis is common in the elderly and the diagnosis can elude even the most experienced surgeon. How do we make an early diagnosis of appendicitis in the elderly with a reduced rate of complications? High index of suspicion is the practice principle. The classical sequence of symptoms is uncommon. In a nutshell however, the presentation of appendicitis in the elderly still follows the classical form of presentation, though more of the elderly patients manifest atypically. It must be restated that awareness is the main thing when it comes to making diagnosis of appendicitis in the elderly. The corner stone of diagnosis is localised tenderness over McBurney's point (Carr NJ, 2000; Horattas MC, et al, 1990)..

The classical presentation is an elderly patient with a sequential progression of acute central abdominal pain migrating to the right lower quadrant of the abdomen. Majority of the patients have nausea. It may be associated with vomiting and low grade fever. There is slight temperature elevation $\left(1^{\circ} \mathrm{C}\right)$, tachycardia, constipation and diarrhoea. If vomiting is more than twice in a patient with suspected appendicitis it indicates a complicated appendicitis or a wrong diagnosis (Carr NJ, 2000; Horattas MC, et al, 1990). What is the cornerstone of diagnosis for acute appendicitis? The basis of diagnosis is classic history of anorexia with periumbilical pain localizing to right iliac quadrant. In an article published earlier pain was found to be the most common complaints followed by anorexia and vomiting in 100, 67 and 59\% respectively (Schumpelick V, et al, 2000). The usual complaint in appendicitis is abdominal pain. This was found in the article reviewed to vary from 92 to $100 \%$ of patients. The pain may be in the right iliac fossa, periumbilical, vague or diffuse. According to this publication the next common symptom was found to be anorexia nausea which was found in $52 \%$ of their patients. Patient may present with a mass in the right iliac fossa, which may come as appendiceal mass or an abscess. Other symptoms include vomiting, fever and diarrhoea. In the same article, tenderness in the right iliac fossa was found in 80 to $99 \%$ of patients. Other signs were abdominal mass, rectal tenderness, and high temperature. Leukocytosis was a very common laboratory finding. This was found in at least 71 to $94 \%$ of patients (Krisher S, et al, 2005). . Palpatory pressure in left iliac fossa may cause pain in the right iliac fossa (Rovsing sign). Other signs that may be elicited 
include, psoas (pain with right thigh extension), pain with internal rotation of flexed thigh, (obturator sign). In retrocaecal appendix, there may be flank tenderness in the right iliac fossa. The diagnosis of appendicitis is difficult in the elderly for many reasons that have been highlighted earlier. Diagnosis of this condition should be expedited in the elderly for good outcome of treatment. Clinical features and definitive investigations are indispensable in making the correct diagnosis of appendicitis in the elderly.

If vomiting occurs first the diagnosis of appendicitis is doubtful. The common sequence of presentation is the sequence of anorexia, then abdominal pain, then vomiting which occur in $95 \%$ of cases. Summarising their findings, the classical diagnostic features of appendicitis are fever, elevated $\mathrm{WBC}$, anorexia, and right lower quadrant (RLQ) pain. In an attempt to improve diagnostic accuracy clinical scoring systems have been developed. In a metaanalysis of diagnostic studies, Anderson concluded that, although individual variables had weak discriminatory power, when combined they have strong predictive power. Diagnostic variable are better combined to improve the diagnosis of appendicitis. The most powerful variables were laboratory tests of inflammation - high WBC, the percentage of neutrophils and $C$ reactive protein levels and clinical indicators such as history of migration of pain and evidence of peritoneal irritation - rigidity and rebound tenderness (Jaffe B, 2005; Naaeder SB, Archampong EQ, 1999). This method has been found to tremendously improve diagnostic accuracy. A prompt diagnosis is invaluable in the management of appendicitis in the elderly. A combination of delay in presentation and misdiagnosis with subsequent delay in surgical intervention contributes to perforation. The slight differences in pathophysiology of appendicitis also contribute to this complication as reported by Carr (Carr NJ, 2000). Remember not to place appendicitis lower than second in the differential diagnosis of acute abdomen in the elderly.

\section{Investigation}

What are the routine preoperative tests we should carry out? While symptoms can guide the selection of ancillary tests in persons under age 40, the prevalence of acute illness with a nonspecific presentation in the elderly dictates a lower threshold for screening. Elderly persons undergoing surgery should have the following routine tests: a fasting glucose level to screen for hidden or ongoing diabetes; a complete blood count to indicate any infection or anaemia and the blood pictures; electrolytes; blood urea nitrogen; creatinine to determine risk of cardiac arrhythmias and postoperative renal failure; chest radiograph to screen for pulmonary disease; and an electrocardiogram (ECG) to detect any ischemia or arrhythmia. All these tests are valuable in the general assessment of the patients for proper outcome of surgery. If patients are not adequately evaluated and all the defects or derangements are corrected before surgery, incorrect management can worsen the morbidity and mortality of the patient. Studies have shown that if these tests have been performed within 3 months prior to admission in persons without new symptoms, they need not be repeated. Nevertheless, most practicing physicians and surgeons repeat the tests within a few days of surgery as a matter of habit (Graber MA, et al, 1999; Wolfe JM, 2000). It is advisable that all these tests be repeated in the elderly each time they are being taken for any operative procedure as the organ systems at that age group are declining in function with low reserve as compared to the young candidates who are being taken for surgery. The elderly must be adequately resuscitated before undergoing any form of surgical procedure. 
These investigations must not be seen in isolation but must be combined with clinical findings for proper assessment and management of patients. Carrying out these investigations astutely is important as many diseases present the same ways appendicitis manifest in the elderly. No time is wasted in taking our time to screen the elderly for other problems in order to reduce the incidence of unnecessary surgeries. Hence there is need for proper assessment by way of investigations. Appendix various locations in the abdomen has anatomical basis. Its intraabdominal location depends on the way it is attached by the mesoappendix. The presenting symptoms therefore vary according to the location of the inflamed portion and the affected contiguous structures. Adequate investigation is indispensable in knowing the exact cause of abdominal pain in the elderly. Appendix is variously located in order of frequency in the low cecal position, the pelvis and the retrocaecal position (Cordon RE, 1986; Paulson EK, 2003). The focus of the investigations should be directed against those conditions that can imitate appendicitis in the elderly. In this age group, the differential diagnosis of acute appendicitis includes the following: diverticulitis perforated peptic ulcer, acute cholecystitis, acute pancreatitis, intestinal obstruction, perforated caecal carcinoma, mesenteric vascular occlusion, and rupturing aortic aneurysm. Although rare, amoebic infection of the caecum with caecal dilation can mimic appendicitis especially in the tropical countries. Infection with salmonella species can also mimic appendicitis. The presence of a cecal malignancy must be seriously considered in the differential diagnosis of appendicitis in the elderly. Many cases of colonic cancers have been diagnosed as appendicitis and had also been treated as such. Risk of perforation is greater, and because of advanced age, mortality and morbidity are elevated in the elderly. In all patients with gastroenteritis, appendicitis must be considered (Freund HR \& Rubinstein E, 1984). The main bearing is that in all cases of abdominal pain in the aged; please consider investigating for appendicitis strongly. All efforts should be made to rule out these pathologies as delay and wrong diagnosis worsen the outcome of appendicitis treatment among the old patients.

What are the values of white blood cell count in this group of patients? The white blood cell count must be noted and urine analysis should be included especially in the elderly patients with acute abdomen. Remember subcaecal or pelvic appendicitis may be associated with microscopic haematuria and leukocytes. The important of the Haemogram is the differential of the white blood cell count. There is a high level of leucocytes count in most of the patients. This is a normal reaction to bacterial infections in the body. In appendicitis of the elderly, this laboratory index is a strong parameter. This parameter is highly rated as it is stated that elevated WBC count and right lower quadrant pain appear to be the most sensitive clinical indicators of appendicitis but are highly nonspecific. Remember no single laboratory parameter is diagnostic. The urea and electrolyte only indicate the function of the kidney. If the patient will need to undergo surgery, the kidney must be function well in order to clear the system of anaesthetic drugs (Oliak D, 2000 et al. Saidi HS\&Adwok JA, 2000). Many of these patients are already having a decline function of their kidneys. The incidence of diabetes is high in this category of patients hence the blood sugar estimation is necessary before anaesthesia.

Imaging studies are important among the many investigations to consider in the assessments of the patients for the purpose of proper management of the aged. These imaging investigations should not exclude the non specific tests such as complete blood count, C reactive protein (CRP), and urinalysis as stated. The definitive diagnosis is easily enhanced with imaging studies such as computed tomography with or without contrast addition of intravenous or oral medium. The addition of contrast enhances its sensitivity. Two other 
imaging studies that are important in the assessment are ultrasound and magnet resonance imaging. The first advocated imaging study is a non ionising study test, the ultrasonography scanning. In most cases if the diagnosis is not certain after ultrasound, computed tomography should be used to confirm or rule out appendicitis. Some surgeons maintain that the clinical diagnosis of appendicitis by a surgeon is sufficient without any radiologic study before surgery. The occasional discovery of normal appendix at the time of surgery may be considered an acceptable false positive clinical diagnosis in order to minimize the occasional error of false negative diagnosis that would result in delayed operation, ruptured appendicitis, and associated complications (Mahadevan M \& Graff L, 2000).

As studies have shown, ultrasonography (US) and computed tomography (CT) scans have demonstrated high efficacy. US has a sensitivity of $75 \%$ to $90 \%$, a specificity of $86 \%$ to $100 \%$, a positive predictive value of $89 \%$ to $93 \%$, and an overall accuracy of $90 \%$ to $94 \%$. CT scanning is even more accurate, with a sensitivity of $90 \%$ to $100 \%$, a specificity of $91 \%$ to $99 \%$, and a positive predictive value of $95 \%$ to $97 \%$. Ultrasound we should know cannot rule out appendicitis but very useful in its confirmation. For the vast majority of patients who present with typical appendicitis, however, obtaining a CT scan may only delay the time of operation and may prove to be unnecessary in the end. It also adds to the cost of care. A reasonable approach for that reason is to reserve the use of radiologic studies for patients with an atypical presentation or in patient populations in whom the possibility of a misdiagnosis is greater. Such patients in which the risk is greater include the young sexually active females with high likelihood of PID, pregnant women (US), and elderly patients with confounding factors. For patients with a classic presentation of appendicitis, radiologic studies are unnecessary (Naoum JJ, et al, 2002. Patrick DA, et al, 2003)

\subsection{Plain abdominal $X$ ray}

One is not always able to diagnose appendicitis from plain abdominal $\mathrm{x}$ ray, but it is helpful. There may be localized air fluid levels, with increased soft tissue density in the lower quadrant of the abdomen. There may be presence of stones, altered right psoas shadow or an abnormal right flank stripe. In general the findings on plain films are non specific and rarely of help in diagnosis of appendicitis (Lawrence Way, 2006).

\subsection{Ultrasonography}

The sensitivity of ultrasound in the diagnosis of appendicitis from several centres has been reported to be as high as $80 \%$, with specificity as high as $90 \%$. Standard abdominal radiography may show a calcified faecolith in the right lower quadrant along with a paucity of gas in the right lower quadrant of the abdomen. A loss of the right psoas shadow may be noted and represents late appendicitis with retroperitoneal inflammation. A perforated or gangrenous appendix may exhibit extra abdominal gas on radiographs, but this occurs in only $1 \%$ of cases. A sentinel loop ileus or a soft-tissue mass with or without gas bubbles also be may seen in advanced cases. Ultrasound may diagnose acute appendicitis, but negative ultrasound does not appear to rule out appendicitis (Naoum JJ, et al, 2002; Patrick DA, et al, 2003). Ultrasound though useful has its own short coming in the diagnosis of appendicitis.

\subsection{Barium contrast}

Barium contrast studies remain a simple, safe, and readily available test that may be helpful. However, ultrasound and CT examinations now are preferred. A barium study assures 
luminal patency of the appendix, colonic wall for mass effects or secondary effects of appendicitis, and right colonic or terminal ileal mucosal disease that may simulate appendicitis. When the barium contrast fills the appendix, a diagnosis of acute appendicitis is very unlikely but not impossible. Up to $10 \%$ to $20 \%$ of normal appendices do not fill during a barium study. These inconsistencies should be noted in the use of barium contrast studies in the diagnosis of appendicitis.

\subsection{Laparoscopy}

Laparoscopy can be both diagnostic and therapeutic for acute appendicitis. Laparoscopy may be indicated in problem patients. In almost all circumstances, a laparoscopy with negative findings is preferred to expectantly watching the appendix rupture. No harm if negative laparoscopy is carried out. When the classical features are present, diagnosis of appendicitis by laparoscopy are not difficult. However in whatever form of presentation, diseases that will mimic appendicitis that do not require operative therapy and can be made worse by operation must be rule out. Such diseases include pneumonia of the bases of the lung, myocardial infarction and pancreatitis among others (Franz MG, et al, 1995). Laparoscopy is very useful in ruling out other intraabdominal problems that may mimic appendicitis in the elderly.

\subsection{Computed tomography}

$\mathrm{CT}$ is the diagnostic test of choice for appendicitis and to rule out abscess formation. It should be employed in cases of elderly appendicitis to avoid delay in diagnosis. The use of CT to delineate abdominal pain in a select population is an excellent tool that the surgeon should not hesitate to use early in patient for evaluation (Saidi HS \& Adwok JA, 2000). CT scan accurately detected appendicitis in $90 \%$ of the cases according to an article published by Storm Dickerson and Horratas. According to Storm and Horratas, CT should be reserved for cases in which suspicion warrants confirmation prior to surgery. Radiologic evaluation should be based on the radiologist interpretation of acute abdominal series (AAS) or computer tomography (CT) or both. CT can be utilized selectively to confirm the diagnosis in equivocal cases. CT in their series was considered positive only if it was diagnostic for or suggestive of appendicitis. Their CT criteria for a positive appendicitis included pericaecal inflammation or visualization of the appendix with inflammation. While the use of CT has opened new avenues in medicine and may be the most significant advance made in the treatment of appendicitis in the elderly over the last 20 years, history and physical examination remains the hallmark of patient evaluation. Note according some authors, appendicitis need to be considered in the differential diagnosis for all acute abdominal pain in the elderly (Horattas MC \& Haught R, 1992). CT scanning may decrease the incidence of appendiceal rupture and also the frequency of exploratory laparotomy for what turns out to be a normal appendix. However, removal of a normal appendix in a symptomatic patient who is thought to have appendicitis, a potentially lethal disease, should not be considered an unnecessary operation. The number of elderly patients and children who die of appendicitis because of failure to operate early enough when the diagnosis is in doubt is much higher than the number of patients who die from a complication following removal of a normal appendix. The morbidity of negative laparotomy is minimal and is much more acceptable than the significantly higher morbidity of a perforated appendix. Unfortunately, after 60 years of age, about $50 \%$ of patients are found to have a ruptured appendix when the operation is finally done. A normal appendix may be difficult to locate on CT examination 
and may require extra scans at finer intervals. Appendicoliths are seen in one fourth of all people as a ring-like or homogenous calcified density on CT. CT imaging has $90 \%$ sensitivity for detecting intraabdominal inflammation. CT findings suggestive of appendicitis include a pericaecal phlegmon or abscess, and small amounts of right lower quadrant intraabdominal free air that signals perforation.

\section{Treatment}

In 1989, Harold Ellis wrote that "the treatment of acute appendicitis is appendectomy - and the sooner it is done, the better" (McCallion J,et al, 1987). This statement is true today as it was many years back in the history of treatment of appendicitis. Controversies now exist in the treatment of appendicitis in the present day. Some now question the rational for removing all inflamed appendices without selective excision of appendix. There is general agreement that the treatment of acute appendicitis is appendicectomy. However, in the elderly it is advisable that if the diagnosis is certain, and surgery is indicated a patient who is fit for surgery; appendicectomy should be carried out for cases of appendicitis in the elderly (Sherlock DJ, 1985). Like any other patients with appendicitis, basic investigations for patients going for surgery must be performed in the elderly. Proper preoperative assessment is very important. The high probability that older patients will require surgery and the increased risk of morbidity and mortality in the elderly necessitate a thorough preoperative assessment in older adults than any other group of patients. Typical postoperative mortality rates of older patients undergoing major intra-abdominal surgery range from 3 to $5 \%$, about twice that of persons under age 65 (Sherlock DJ, 1985).. What we need to do is to identify any significant risk factors of adverse outcomes and to provide recommendations for the evaluation and management of these risk factors. The high prevalence of multiple comorbidities in the elderly necessitates a comprehensive history and physical examination. The treatment of appendicitis in the elderly should be individualised. These patients have varied pathologies above sixty years of age. Treat appendicitis as indicated individually in the elderly. No single modus operandi can be followed but surgical principles should be observed. The type of procedure as well as the presence of several risk factors can be identified by a review of the patient's medical history. In general, a comprehensive physical examination should be conducted. A proper evaluation of clinical presentation allows the index of suspicion to be set at the proper level so that a threshold for intervention can be reached before the appendix ruptures. If after proper assessment of patient, appendix is still removed with the idea of what constitute unnecessary surgery, no harm is done. According to Condon, the removal of a normal appendix in appropriate clinical circumstances never constitutes an unnecessary appendectomy (Condon RE, 1986).

\subsection{Preoperative assessment}

All derangements found in the assessment of the patients should be corrected before surgery. Anaemia should be corrected. Dehydration and renal functions should be corrected. High blood sugar if present should be controlled. All other deranged parameters involving other organs apart from gastrointestinal system should not be disregarded. Proper and appropriate preoperative treatment depends most time on the type of presentation of appendicitis. Are we dealing with simple appendicitis, appendiceal mass or perforated appendicitis with peritonitis? In other word is it an elective patient or an emergency patient? Where the cases are patients for elective appendicectomy, cessation of smoking prior to 
surgery is helpful and should be undertaken at least 2 weeks prior to surgery. Training in coughing and deep breathing exercise should be undertaken prior to surgery. If chronic obstructive pulmonary disease (COPD) is present, aggressive use of bronchodilators should be implemented both before and after the operation. Prophylaxis of thromboembolic events is based on the type of procedure and level of risk of the patient. In high-risk general surgical patients, e.g., those with previous history of thromboembolic phenomenon who is to undergo surgery especially major one, a low dose heparin should be administered before and continued after surgery. Heparin 5000 to $7500 \mathrm{U}$ every 12 hours begun on the day of surgery is effective. Low-molecular-weight heparin twice a day with or without intermittent pneumatic compression is also effective.

\subsection{Preoperative analgesia}

Should we or should we not give pain killer before surgery in order not to mask the diagnosis of appendicitis where we are not yet certain? There has been a growing concern of IV analgesia masking an ongoing intraabdominal catastrophe, leading the surgeon to miss the diagnosis and potentially endanger the patient. This code of belief has been challenged in recent times, however. In fact, it has been established that IV analgesia results in a significant pain reduction without concurrent normalizing effects on the abdominal examination. There is strong evidence suggesting that contrary to traditional teaching, it is, in fact, safe to administer opioid analgesics and other forms of analgesia in the setting of surgical evaluation of acute abdomen without increasing the chance of misdiagnosis. One can still be able to elicit all the necessary signs of the abdomen even after analgesia. It is also humane and since it will completely mask the signs, patients with pain should be relieved with pain killer before surgery. Patient should be properly assessed by the anaesthesiologist to ascertain the fitness and grade of fitness of patient for surgery. No patient should be rushed for surgery without appropriate consideration and duly signed informed consent obtained. Patient or patient relation must fully understand the procedure to be carried out and the possible outcome of the surgery. Delay treatment and misdiagnosis have been found to correlate with perforation of appendicitis. In cases of suspected appendicitis where the index of suspicion is too low to mandate immediate operation, active observation, comprising in patient admission with serial clinical and laboratory examinations, is an acceptable and valuable tool, both in reducing unnecessary appendectomies and preventing missed diagnoses (Watters JM, et al, 1996). Even though delayed surgical management is associated with increased risk for Appendiceal rupture in the elderly undue operation should be reduced. We should remember that extreme of ages are associated with high risk of surgical procedures. Delay in the elderly should be avoided.

\subsection{Intraoperative management}

Appropriate form of anaesthesia should be administered to the patient. Considerations should be given to individual patient. General or regional anaesthesia can be prescribed depending on the patient and the nature of operation to be carried out. Is patient going for simple appendicectomy or to undergo exploratory laparotomy? Treatment is seen in two major categories, simple appendicitis and complicated appendicitis. The complicated cases include appendiceal mass, appendiceal abscess and ruptured appendicitis with peritonitis among others. The peritonitis may be localised or generalised depending on how the body is able to wall off the offending agent (Paranjape, C., et al, 2007) 


\subsection{Simple appendicectomy}

In cases of certainty of diagnosis of uncomplicated acute appendicitis, appendectomy should be performed as an emergency procedure. If we need to lay further emphasis on the type of incisions suitable for this surgery, the recommended incision for a routine appendectomy (uncomplicated cases) is a transverse incision (Brown CV, et al, 2003). Both midline and grid iron incision can be used equally. The midline has an added advantage for easy extension of the incision if the diagnosis is found to be something else that may require a complete laparotomy. Exposure of the appendix through this incision is much better than that obtained through the classic McBurney incision, particularly in patients who have a retrocaecal appendix or are obese. The gridiron, or muscle-splitting, incision (McBurney incision) is the one most widely used for uncomplicated appendicitis, largely because of surgical tradition rather than its particular utility. The exposure through a McBurney incision can be awkward, especially for a retrocaecal appendix, unless the appendix lies immediately below the incision. If necessary, the incision can be extended medially, partially transecting the rectus sheath, but this manoeuvre is usually helpful only for a pelvic appendix (Kaminski A, et al, 2005). If the diagnosis of acute appendicitis is in doubt and exploratory laparotomy is indicated, a vertical midline incision is appropriate. If an appendiceal mass is encountered, the midline incision can be closed and a more direct approach to the lesion made through a right lower quadrant incision.

\subsection{Open technique}

The benchmark incision for the management of appendicitis has been through a small right lower quadrant incision. Patient abdomen should be palpated under anaesthesia. McBurney's point marks the bearing of appendicectomy incision. It does not generally indicate the tip of the appendix but locates the base. In general, an inferior incision below the area of maximal tenderness helps in rotating the caecum into the wound. The McBurney incision is the classical oblique appendectomy incision through McBurney's point to the lateral edge of the rectus sheath; it can be extended into the lateral rectus sheath, if necessary. It is quite cosmetically acceptable when healed. On the other hand, a skin line or transverse incision placed 1 to $2 \mathrm{~cm}$ medial to the anterosuperior iliac spine can be used. These incisions are performed with a muscle-splitting technique through all layers lateral to the rectus abdominis muscle. The incision is continued through the superficial fascia until the external oblique muscle aponeurosis is exposed. The fibres of the aponeurosis are opened, and the muscle fibres are bluntly separated, as are the fibres of the internal oblique and transverse abdominis muscles. The peritoneum is opened and intraperitoneal cultures can be obtained. The caecum is mobilized into the wound, and the appendix is mobilized as adhesions are bluntly and/or sharply dissected. The taeniae of the colon converge at the base of the appendix, an arrangement that helps in locating this structure at operation. The base of the appendix always lies at the confluence of the taeniae. In mobile appendices, the mesoappendix can be grasped near the tip of the appendix with a clamp. The appendix can be grasped with a Babcock at its base. The mesoappendix can be ligated en masse with no. 3-0 absorbable suture if the pedicle is not too large or edematous (Brown CV, 2003; Condon RE, 1986).

Ligation of the mesoappendix usually is performed from the distal tip to the base of the appendix (antegrade appendicectomy), but sometimes reversing the sequence can facilitate appendectomy (retrograde appendicectomy). The accessory branch of the posterior cecal artery securely should be ligated. The appendix is double clamped with straight hemostats across the base, leaving sufficient space between clamps to permit passage of the cautery or 
scalpel. The space between clamps can be crushed or milked prior to clamping to minimize contamination into the peritoneal cavity. The appendix is amputated with the scalpel or with cautery, and the appendix and the attached clamp are dropped into a small basin to avoid contamination. The appendiceal stump is then doubly ligated with $2-0$ absorbable or delayed absorbable suture. The appendiceal stump may be cauterized to prevent mucocele formation or inverted with a purse string suture or Z-stitch in the caecum. If this is done, a purse-string suture of medium silk is placed around the base of the appendix. The circumference of the purse-string suture should be large enough to permit easy inversion of the stump. A half-knot is placed in the silk; after the appendix is amputated, the stump is inverted and the purse-string is drawn tight. The site of the inversion should be covered with mesoappendix or any convenient flap of fat (Brown CV, 2003; Condon RE, 1986, Ellis $H, 1989)$. However, inversion of the stump is no longer considered necessary by many authors. It is not recommended when the appendix is inflamed. Copious irrigation with saline or antibiotic solution should be performed in cases of perforated appendicitis to reduce the risk of a pelvic. The peritoneum and muscular fasciae are usually closed with a running absorbable suture. The skin can be closed in nonperforated cases of appendicitis, but delayed primary closure is routine in cases of ruptured appendicitis.

\subsection{Laparoscopy appendectomy}

This procedure has revolutionized the removal of appendix with minimal morbidity and mortality. Since it was first described by Semm in 1983, laparoscopic appendectomy has gained acceptance as both a diagnostic and treatment method for acute appendicitis. It is safe and effective. There is less surgical tissue trauma, a better postoperative course, the ability to explore the entire abdominal cavity, assessment for the existence of associated pathologies, better cosmetic results, and a rapid return to normal activity. The ability to completely evaluate the pelvis and the entire peritoneal cavity when a healthy appendix is found is extremely important for the surgeons as many conditions in the elderly that mimic appendicitis can be rule out immediately (Fitz HR, 1986). Removing a normal appendix during laparoscopic evaluation for suspected acute appendicitis can be performed with no added morbidity or increased length of hospitalization as compared to diagnostic laparoscopy. The laparoscopic approach offers the advantage of shorter hospitalization and less morbidity, with a lower rate of abdominal wall infection. There is no significant difference in the rate of abscess formation in patients with perforated appendicitis. The interval until the patient may return to work is shortened and postoperative pain is decreased with the laparoscopic approach, and the quality of life appears to improve faster than when the traditional open approach is used. Obese patients may benefit substantially from the laparoscopic approach as it obviates the problems of a large incision, strong retraction, prolonged surgery, and wound infection that are associated with open surgery in the obese (Fitz HR, 1986; Hui TT et al, 2002).The disadvantages of the laparoscopic approach have been longer duration of surgery and higher costs. However, the length of surgery has been significantly reduced with improved surgical skills and experience. Also, the immediate cost difference appears to be diminished with the use of reusable laparoscopic equipment, and when the more rapid return to work and other activities is included, the laparoscopic approach turns out to be extremely cost effective. It is increasingly recommended as the procedure of choice for the diagnosis and treatment of suspected acute appendicitis.

The detail procedure is beyond the scope of this write up. See other references for details of the procedure. How does the laparoscopic approach to appendectomy compare with that of the 
open approach? Laparoscopic appendectomy is superior to the open approach in terms of decreased postoperative wound infections and recovery time. In a large review, patients who underwent laparoscopic appendectomy were found to be as follows when compared with patients who underwent open appendectomy: Are about half as likely to develop postoperative wound infections (odds ratio 0.47, 95\% confidence interval between 0.36 and 0.62) Have decreased pain on postoperative day 1 by the visual analog score of $8 \mathrm{~mm}$ on a scale of $100 \mathrm{~mm}$ (95\% confidence interval between 3 and $13 \mathrm{~mm}$ ) Have reduced length of hospital stay by 0.7 days (95\% confidence interval between 0.4 and 1.0) Have reduced time of recovery in terms of earlier return to normal activity, work, and sport by 6 days (95\% confidence interval between 4 and 8 days), 3 days (95\% confidence interval between 1 day and 5 days), and 7 days ( $95 \%$ confidence interval between 3 days and 12 days), respectively Have increased cost of the operation, but decreased cost outside the hospital Have reduced rates of negative appendectomies or unestablished final diagnosis. But the laparoscopic appendectomy was inferior to the open appendectomy in the following ways: Nearly three times as likely to develop postoperative intraabdominal abscesses (odds ratio $2.77,95 \%$ confidence interval between 1.61 and 4.77 ) Increased duration of surgery by 14 minutes ( $95 \%$ confidence interval between 10 minutes and 19 minutes) The reviewers concluded that the laparoscopic appendectomy would be advantageous over the open appendectomy in most cases of suspected appendicitis, except in patients in whom laparoscopy is contraindicated or unfeasible, in patients with gangrene, and patients with perforated appendicitis. In these patients, the laparoscopic approach carries a higher risk of intraabdominal infections (Sauerland S et al, 2004, van Sonnenberg E et al, 1987; Vargas HI, et al. 1994)

What would have been done if a tumour had been discovered in appendix? How often are tumours found in the appendix? What is the most common tumour of the appendix? What is the usual presentation of appendiceal tumour? The most common type of appendiceal tumour is carcinoid, usually on the tip of the appendix. Carcinoid, comprising $77 \%$ of appendiceal tumours, was discovered in only $1.4 \%$ of 1,000 consecutive appendectomies (Dymock RB, 1977). If the carcinoid tumour is small, a simple appendectomy is adequate; if the tumour is large, a more extensive resection is indicated. A retrospective literature review noted that tumours larger than $2 \mathrm{~cm}$ had a much higher incidence of regional metastasis than smaller ones. For this reason, simple appendectomy for tumours smaller than $2 \mathrm{~cm}$ and right hemicolectomy for tumours larger than $2 \mathrm{~cm}$ is recommended. Primary adenocarcinoma of the appendix is exceedingly rare $(0.1 \%)$. The usual presentation of an appendiceal tumour is similar to that of appendicitis.

\subsection{Incidental appendicectomy}

What are the arguments for and against performing an incidental appendectomy during this patient's laparoscopic examination? What evidence supports incidental appendectomy in this patient? Removing the appendix during a negative exploration is controversial. The argument for incidental appendectomy is that the absence of the organ obviates any future question of appendicitis should the patient develop recurrent abdominal pain. The argument against incidental appendectomy is largely the risk of peritoneal or wound infection, especially during clean procedures in which resection through the appendiceal stump may spill the contents of the caecum. In a prospective randomized study of 139 trauma patients, there was no significant difference in intraperitoneal or wound infections between the patients who received incidental appendectomy and the control group who did not. The factors that would sway the surgeons to perform incidental appendectomy include easy access to the appendix 
and technical feasibility, contaminated peritoneum (i.e., concomitant bowel content spillage), young age, and the likelihood of future abdominal pains (e.g., history of PID, family history of Crohn's disease). In this young patient with a strong history of recurrent RLQ abdominal pain, an incidental appendectomy is justified. Vargas HI et al, 1994)

\subsection{Peritoneal fluid culture}

When the peritoneum is opened, cloudy intraperitoneal fluid is noted. A culture and sensitivity sample of the fluid is sent to the microbiology laboratory. Further dissection reveals a gangrenous appendix with distal perforation in the pelvic brim. How valuable is the practice of sending a sample of the intraperitoneal fluid for bacterial culture and sensitivity? Not valuable. In a retrospective study of 308 pediatric patients, the results of routine culture and sensitivity did not lead to improvement in patient management. Only $16 \%$ of the patients had their antibody management changed as a result of the culture and sensitivity. However, specific antibiotic treatment based on culture result was associated with increased infectious complications. The use of empiric antibiotics without modification to culture results was associated with a lower incidence of infectious complications, fever duration, and length of hospitalization. The practice of routine culture is not helpful in most cases of acute appendicitis, and empiric broad-spectrum antibiotic coverage should be adequate (Van Sonnernberg, et al, 1987)

\subsection{Complicated appendicitis}

We shall briefly consider the management of the complicated cases of appendicitis. The three complications that shall be considered include appendiceal mass, appendiceal abscess, and perforated appendicitis with peritonitis. These are various stages in the pathological processes of appendicitis. The development of each depends on how well the body can wall off the offending agents. If these complications are well tackled in the Elderly patients, the morbidity and mortality increase sharply.

\subsection{Appendiceal mass treatment}

Appendiceal mass are managed expectantly. The diagnosis can be made preoperatively or at induction of anesthesia when the patient is well relaxed and the abdomen can easily be re assessed. If appendiceal mass is detected at any state, the operation should be abandoned in favor of conservative management. Some of the patients may be having malignancy masquerading as appendicitis. If the decision has been made to manage the patient expectantly, patient should be admitted into the hospital. Intravenous fluid should be instituted, patient should inititialy be placed on nil per os. Intravenous antibiotics should be administered covering aerobic and anaerobic organism as indicated under pathology above. The patient should be kept under close observation with the pulse closely followed because tachycardia is one of the first signs of sepsis. Other clinical parameters to follow include change in pain quality, white blood cell counts, differential counts, and serial radiologic evaluations including ultrasound and/or CT. Failure to respond to therapy after 24 to 48 hours indicates that operative intervention should be reconsidered. Patients with well-formed periappendiceal abscesses can undergo CT-guided placement of pigtail drainage catheters to help resolve the abscess more rapidly, rather than depending on the abscess to drain internally into the cecum.

Naturally appendiceal mass can resolve completely or develop into an abscess. The vital signs monitoring and serial ultrasound and other possible imaging examinations will settle 
the outcome of the mass. If the mass forms an abscess, the abscess should be drained. If the mass resolves completely patient should have interval appendicectomy. If a distinct mass in the right iliac fossa is palpated and the patient has no systemic manifestations, the patient is kept nil per os (NPO) while intravenous fluids and broad-spectrum antibiotics are given to cover enteric organisms. There are growing schools of thoughts regarding the management of appendiceal mass. Apart from the usual method adopt by the majority of surgeons as described above, many have proposed a more aggressive methods of treatments of appendiceal mass. Another group of surgeons believe that patient should have immediate appendicectomy following appendiceal mass resolution before patient is discharged from the hospital (Terasawa T, et al, 2004). A school of thought has also proposed a more aggressive approach of immediate right hemicolectomy following a diagnosis of appendiceal mass. Each has its own advantages and disadvantages. The more aggressive method sorts out the cases at once even though it may turn out to be an overtreatment for the patients. Many of the patients may end up not requiring right hemicolectomy.

\subsection{Appendiceal abscess treatment}

Patient may present from the onset into the hospital as a case of appendiceal abscess especially among the elderly people. Some other patients may develop appendiceal abscess during expectant management for cases of appendiceal masses. The treatment however is the same in most patients. The abscess should be drained. The drainage of the abscess should be done extra peritoneally avoiding contamination of the general peritoneal cavity. The usual grid iron incision can be used and the peritoneum is not opened. The abscess is drained extra peritoneally with a drain inserted and directed out into the cavity of the abscess. If the peritoneum is breached and pus spills into the cavity, generalize peritonitis may ensue which will worsen the outcome of the abscess drainage. The conventional treatment of this patient further involves an interval appendicectomy which should probably be carried out 6-10 weeks after the initial sickness (Terasawa T, et al, 2004). Age passé is not a contraindication to surgery of interval appendicectomy in the elderly. Complications of appendiceal abscess include pelvic, subphrenic and intraabdominal abscess, faecal fistula, peritonitis, pyelonephritis, venous thrombosis, and intestinal obstruction. Septicaemia, pneumonia, septic shock, renal failure, and pulmonary embolus can lead to death in the most advanced or neglected cases. It is relatively safe to remove the appendix in virtually any patient. However, if there are significant medical contraindications to surgery in a nontoxic patient with a clear diagnosis of an appendiceal abscess, a nonoperative approach can be considered (Fitz HR, 1986).

In patients with perforated appendicitis, is there an alternative to immediate appendectomy? Yes, percutaneous drainage and interval appendectomy may be an alternative. If the appendiceal abscess is known to be well loculated and walled off on CT and the patient is not septic, one may percutaneously drain the abscess cavity in lieu of immediate appendectomy, laparoscopic or open, and treat with antibiotics for a few weeks. The patient returns later to have the appendix resected when the inflammation has decreased. Reports indicate a success rate of $70 \%$ to $90 \%$. The benefits of percutaneous drainage under radiologic guidance include precise anatomic identification of complex, multiloculated abscess; avoidance of operation for drainage without appendectomy; temporization of high-risk patients; and temporization of emergency appendectomy for an elective appendectomy. Interval appendectomy reportedly has been performed with the laparoscopic approach safely and effectively. Not all surgeons support this approach, however, and they continue to prefer open appendectomy and drainage (Van Sonnernberg, et al, 1987). 


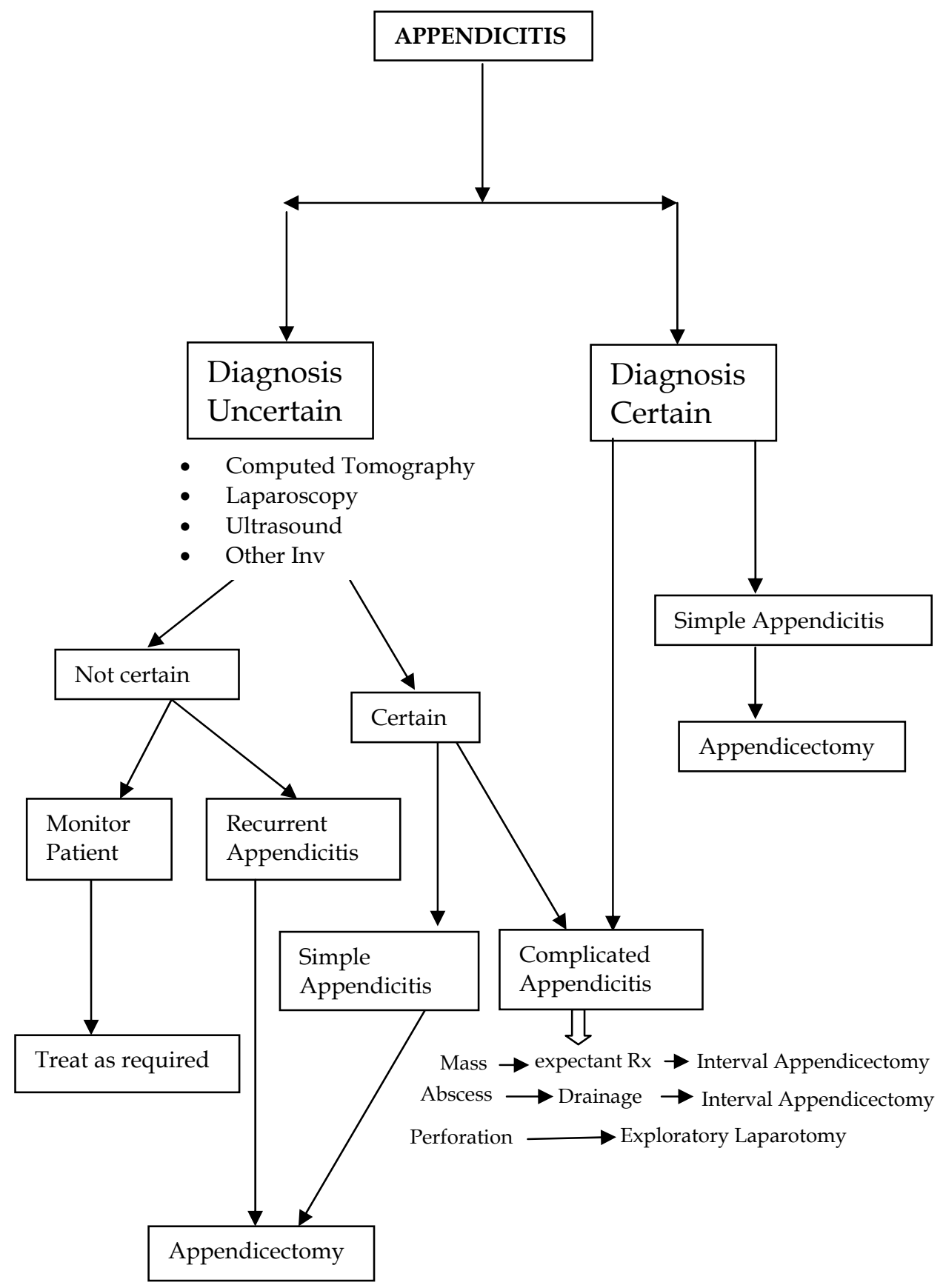

Fig. 1. Simple Management Pedigree of Appendicitis in the Elderly 


\subsection{Perforated appendicitis with peritonitis}

Delay in seeking for medical care appears to be the principal reason for perforations in appendicitis of the elderly. The disease is allowed to progress through its natural course with alteration and this result in perforation at presentation. The appendicitis has progressed to perforation by the time of appendicectomy in people over 60 years of age. Most mortalities of appendicitis occur in this group of patients. Localised peritonitis results from microscopic perforation of gangrenous appendix, while spreading or generalised peritonitis implies gross perforation into the free peritoneal cavity. Patients with perforated appendicitis with generalised peritonitis should be well resuscitated before embarking on any surgical intervention. This category of patient requires exploratory laparotomy, appendicectomy and copious peritoneal larvage (Blomqvist P, et al, 2001). The mortality among these patients is high therefore patient must be adequately resuscitated before embarking on surgery (Lawrence Way, 2006). Management of appendicitis in the elderly is summarised in figure 1.

\section{Conclusion}

These initial investigations should include WBC, CRP (if available) and urinalysis. A higher index of suspicion with liberal early utilization of CT in uncertain cases may result in more appropriate management of these cases (Storm-Dickerson T.L. \& Horattas M.C, 2003). A high index of suspicion is necessary to guard against misdiagnosis, especially in the elderly. We should exercise caution as delay in presentation and diagnosis are associated with higher rates of appendiceal perforations and hence higher morbidity and mortality. Appendicitis needs to be considered in all cases of acute abdomen in the elderly. A high degree of index of suspicion should be maintained always. Equivocal cases should undergo early computed tomography scan. This will facilitate appropriate and timely surgical interventions. The complications that may follow Appendicectomy commonly are wound infection, intraabdominal abscess, faecal fistula, pylephlebitis, and intestinal obstruction. The common organisms include anaerobic Bacteroides species and the aerobes Klebsiella and Enterobacter species and E coli. Successful management of acute appendicitis depends on early diagnosis and early surgical intervention. Elderly patients, who present to emergency departments with abdominal pain suspicious of appendicitis, should have an early surgical consultation and laboratory investigations to rule out appendicitis.

In dealing with wound infections following Appendicectomy in the elderly patients, the skin and subcutaneous tissue should be opened. The wound should be packed with salinesoaked gauze and reclosed with Steri-Strips in 4 to 5 days. Intraabdominal abscesses are common in patients with a perforated or gangrenous appendix. Intraabdominal abscesses are suspected when a patient with appendicectomy presents with recurrent fever, malaise, and anorexia. Computed tomography can be done to make the diagnosis of intraabdominal abscesses. Intraabdominal abscesses should be drained either operatively or percutaneously under CT or ultrasound guidance. Faecal fistula is a possible complication following appendicectomy. Many fistulas will close spontaneously if there is no anatomic basis. Those that do not close spontaneously and has anatomic reasons should be operated (Hardin D, 1999). The strong association between delay in presentation and appendiceal perforation supported the proposition that appendiceal perforation is the advanced stage of acute appendicitis; however, previous epidemiological studies also have suggested alternatively that non-perforated and perforated appendicitis may be different diseases (BOR-FUH SHEU, TE-FA, 2007). In caring for the elderly patient, a high index of suspicion and an 
awareness of the insidious symptoms of acute abdominal disease are mandatory. All aged patients with sudden lower abdominal pains should be screened for possibility of appendicitis. Appendicitis in the elderly is a difficult problem with a high incidence of atypical presentation resulting in incorrect diagnosis and consequent delay in medical care. This lead to relatively high rates of perforation often with associated postoperative complications and a high mortality (Hardin D, 1999).

\section{References}

Alvarado A. (1986). A practical score for the early diagnosis of acute appendicitis. Ann. Emerg. Med. 15: 557-64.

Paranjape C., Dalia S., Pan J., Horattas M. (2007) Appendicitis in the elderly: a change in the laparoscopic era Surg Endosc 21: 777-781 DOI: 10.1007/s00464-006-9097-4

Barcia JJ, Reissenweber N. (2002)Neutrophil count in the normal appendix and early appendicitis: diagnostic index of real acute inflammation. Annals of Diagnostic Pathology; 6(6):352-356.

Birnbaum BA, Wilson SR. (2000). Appendicitis at the millennium. Radiology; 215(2):337-348.

Blomqvist P, Andersson R, Granath F. (2001) Mortality after appendectomy in Sweden, 1987-1996. Ann Surg; 233:455-60.

Brown CV, Abrishami M, Muller M, Velmahos GC. (2003). Appendiceal abscess: immediate operation or percutaneous drainage? American Surgeon; 69(10):829-832

Burns RP, Cochran JL, Russell WL, Bard RM. (1985) Appendicitis in mature patients. Ann. Surg.; 201: 695-704.

Carr NJ. (2000). The pathology of acute appendicitis. Annals of Diagnostic Pathology; 4(1):46-58.

Condon RE. Acute appendicitis. (1986) In: Sabiston DC. Davis Christopher Textbook of Surgery. Vol. 13. Philadelphia, PA: WB Saunders;:967-982.

Ellis H. Appendix. (1989) In: Schwartz \& Ellis, editor. Maingot's Abdominal Operations. Norwalk, Conneticut: Appleton \& Lange,: 953-977.

Fitz HR. (1886) Perforating inflammation of the vermiform appendix; with special reference to its early diagnosis and treatment. Trans. Assoc. Am. Physicians; 1: 107-44.

Franz MG, Norman J, Fabri PJ. (1995) Increased morbidity of appendicitis with advancing age. Am. Surg.; 61: 40-4.

Freund HR, Rubinstein E. (1984) Appendicitis in the aged. Is it really different? Am. Surg.; 50: 573-6.

Friedell ML, Perez-Izquierdo M. (2000) Is there a role for interval appendectomy in the management of acute appendicitis? American Surgeon; 66(12):1158-1162

Graber MA, Ely JW, Clarke S,. (1999) Informed consent and general surgeons' attitudes toward the use of pain medication in the acute abdomen. Am J Emerg Med.; 17:113-116.

Gupta H, Dupuy D. (1997) Abdominal emergencies: has anything changed? Surg Clin North Am; 77:1245-64.

Hale D, Molloy M, Pearl R, et al. Appendectomy: (1997) A contemporary apprasial. Ann Surg; 225:252-61.

Hardin D (1999) Acute appendicitis: review and update. Ann Fam Phys; 60: 2027-36

Hogan MJ. (2003) Appendiceal abscess drainage. Techniques in Vascular $\mathcal{E}$ Interventional Radiology; 6(4):205-214.

Horattas MC, Guyton DP, Wu D. (1990) A reappraisal of appendicitis in the elderly. Am. J. Surg.; 160: 282-5. 
Horattas MC, Haught R. (1992) Managing appendicitis in the elderly patient. AORN J.; 55: 1282-54.

Hui TT, Major KM, Avital I, Hiatt JR, Margulies DR (2002) Outcome of elderly patients with appendicitis: effect of computed tomography and laparoscopy. Arch Surg 137: 995-998;

Kaminski A, Liu IL, Applebaum H, Lee SL, Haigh PI. (2005) Routine interval appendectomy is not justified after initial nonoperative treatment of acute appendicitis. Archives of Surgery; 140 (9):897-901

Kraemer M, Franke C, Ohmann C, Yang Q, (2000) Acute Abdominal Pain Study Group. Acute appendicitis in late adulthood: incidence, presentation, and outcome. Results of a prospective multicenter acute abdominal pain study and a review of the literature. Langenbecks Archives of Surgery; 385(7):470-481.

Krisher S, Browne A, Dibbins A, Tkacz N. (2001) Intra-abdominal abscess after laparoscopic appendectomy for perforated appendicitis. Arch Surg; 136:438-41.

Langenscheidt P, Lang C, Puschel W, Feifel G. (1999); High rates of appendicectomy in a developing country: an attempt to contribute to a more rational use of surgical resources. European Journal of Surgery 165(3):248-252.

Lau WY, Fan ST, Yiu TF, Chu KW, Lee JM. (1985) Acute appendicitis in the elderly. Surg. Gynecol. Obstet.; 161: 157-60.

Lawrence W.W. 2006. Appendix. In:, Current surgical diagnosis and treatment. Gerard Doherty 648-653Lange Medical Books. ISBN 0-07-142315-X.

Lee J. F. Y., Leow C. K., Lau W. Y. Appendicitis In The Elderly. aust. N.Z. J. Surg. (2000) 70, 593-596

Lin CJ, Chen JD, Tiu CM. (2005) Can ruptured appendicitis be detected preoperatively in the ED? Am. J. Emerg. Med.; 23: 60-66

Mahadevan M, Graff L. (2000) Prospective randomized study of analgesic use for ED patients with right lower quadrant abdominal pain. Am J Emerg Med.;18:753-756.

Maxwell JM, Ragland JJ. (1991) Appendicitis, improvements in diagnosis and treatment. Am. Surg.; 57: 282-5.

McCallion J, Canning GP, Knight PV, McCallion JS. (1987) Acute appendicitis in the elderly: A 5-year retrospective study. Age Ageing; 16: 256-60.

McHale PM, Lo Vecchio F. (2001) Narcotic analgesia in the acute abdomen-a review of prospective trials. Eur J Emerg Med.; 8:131-136.

Naaeder SB, Archampong EQ. (1999) Clinical spectrum of acute abdominal pain in Accra, Ghana. West African Journal of Medicine; 18(1):13-16.

Naoum JJ, Mileski WJ, Daller JA,. (2002). The use of abdominal computed tomography scan decreases the frequency of misdiagnosis in cases of suspected appendicitis. Am J Surg.; 184:587-589

Okafor PI, Orakwe JC, Chianakwana GU. (2003) Management of appendiceal masses in a peripheral hospital in Nigeria: review of thirty cases. World Journal of Surgery; 27(7):800-803.

Oliak D, Yamini D, Udani VM (2000). Can perforated appendicitis be diagnosed preoperatively based on admission factors? J. Gastrointest. Surg.; 4: 470-74.

Omundsen M, Dennett E. (2006) Delay to appendicectomy and associated morbidity: a retrospective review. ANZ J. Surg.; 76: 153-5.

Paajanen H, Kettunen J, Kostiainen S. (1994) Emergency appendectomies in patients over 80 years. Am. Surg.; 60: 950-3.

Patrick DA, Janik JE, Janik JS, (2003). Increased CT scan utilization does not improve the diagnostic accuracy of appendicitis in children. J Pediatr Surg.; 38:659-662. 
Paulson EK, Kalady MF, Pappas TN. (2003) Suspected appendicitis. N Engl J Med.; 48:236-242.

Peltokallio P, Jauhianinen K. (1970) Acute appendicitis in the aged patient. Arch. Surg.; 100: 140-3.

Rao P, Rhea J, Rao J. (July 1999) Plain abdominal radiographs in clinically suspected appendicitis: diagnostic yield, resource use, and comparison with CT. Am J Emerg Med.; 17:325-9.

Saidi HS, Adwok JA. (2000) Acute appendicitis: an overview. East African Medical Journal; 77(3):152-156.Sauerland S, Lefering R, Neugebauer EAM. Laparoscopic versus open surgery for suspected appendicitis (Cochrane Review). In: The Cochrane Library. Chichester, UK: John Wiley and Sons; 2004:2.

Schumpelick V, Dreuw B, Ophoff K, Prescher A. (Feb 2000) Appendix and cecum, embryology, anatomy, and surgical applications. Surg Clin North Am; 80:295-318.

Semm K. (1985) Endoscopic appendectomy. Endoscopy(1983) 15: 59- 64

Sherlock DJ. Acute appendicitis in the over-sixty age group. Br. J. Surg.; 72: 245-6.

Sheu B.-F.; Chiu T.-F.; Chen J.-C; Tung M.-S.; Chang M.-W.; Young Y.-R. (2007) ANZ J. Surg.; 77: 662-666 doi: 10.1111/j.1445-2197.2007.04182.x

Sivanesaratnam V. (2000) The acute abdomen and the obstetrician. Best Practice E Research in Clinical Obstetrics \& Gynaecology; 14(1):89-102.

Smithy WB, Wexner SD, Dailey TH. (1986) The diagnosis and treatment of acute appendicitis in the aged. Dis. Colon Rectum; 29: 170-3.

Storm-Dickerson T L, Horattas MC, (2003) What have we learned over the past 20 years about appendicitis in the elderly? American journal of surgery; 185 198-201.

Tehrani H, Petros J, Petros J, . (1999) Markers of severe appendicitis. Am Surg; 65:453-5.

Temple C, Huchcroft S, Temple W. (1995) The natural history of appendicitis in adults, a prospective study. Ann Surg; 221:279-82.

Terasawa T, Blackmore CC, Bent S, Kohlwes RJ. (2004) Systematic review: computed tomography and ultrasonography to detect acute appendicitis in adults and adolescents. Annals of Internal Medicine; 141(7):537-546.

Van Sonnenberg E, Wittich GR, Casola G, (1987). Periappendiceal abscesses: percutaneous drainage. Radiology. 163:23-26.

Vargas HI, Averbook A, Stamos MJ. Appendiceal mass: conservative therapy followed by interval laparoscopic appendectomy. Am Surg. 1994;60:753-758

Vorhes CE. (1987) Appendicitis in the elderly: The case for better diagnosis. Geriatrics; 42: 89-92

Watters JM, Blakslee JM, March RJ, Redmond ML. (1996) The influence of age on the severity of peritonitis. Can J. Surg.; 39: 142-6.

Wolfe JM, Lein DY, Lenkoski K, (2000). Analgesic administration to patients with an acute abdomen: a survey of emergency medicine physicians. Am J Emerg Med.; 18:250-253.

Yamini D, Hernan V, Bongard F, (1998). Perforated appendicitis: is it truly a surgical urgency? Am Surg; 64:970-5.

Yang HR, Want YC, Chung PK. (2005) Role of leukocyte count, neutrophil percentage, and Creactive protein in the diagnosis of acute appendicitis in the elderly. Am. Surg.; 71: 344-7. 


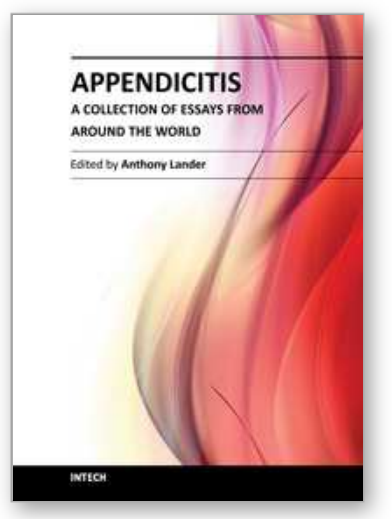

\author{
Appendicitis - A Collection of Essays from Around the World \\ Edited by Dr. Anthony Lander
}

ISBN 978-953-307-814-4

Hard cover, 226 pages

Publisher InTech

Published online 11, January, 2012

Published in print edition January, 2012

This book is a collection of essays and papers from around the world, written by surgeons who look after patients of all ages with abdominal pain, many of whom have appendicitis. All general surgeons maintain a fascination with this important condition because it is so common and yet so easy to miss. All surgeons have a view on the literature and any gathering of surgeons embraces a spectrum of opinion on management options. Many aspects of the disease and its presentation and management remain controversial. This book does not answer those controversies, but should prove food for thought. The reflections of these surgeons are presented in many cases with novel data. The chapters encourage us to consider new epidemiological views and explore clinical scoring systems and the literature on imaging. Appendicitis is discussed in patients of all ages and in all manner of presentations.

\title{
How to reference
}

In order to correctly reference this scholarly work, feel free to copy and paste the following:

Stephen Garba and Adamu Ahmed (2012). Appendicitis in the Elderly, Appendicitis - A Collection of Essays from Around the World, Dr. Anthony Lander (Ed.), ISBN: 978-953-307-814-4, InTech, Available from: http://www.intechopen.com/books/appendicitis-a-collection-of-essays-from-around-the-world/appendicitis-inthe-elderly

\section{INTECH}

open science | open minds

\author{
InTech Europe \\ University Campus STeP Ri \\ Slavka Krautzeka 83/A \\ 51000 Rijeka, Croatia \\ Phone: +385 (51) 770447 \\ Fax: +385 (51) 686166 \\ www.intechopen.com
}

\author{
InTech China \\ Unit 405, Office Block, Hotel Equatorial Shanghai \\ No.65, Yan An Road (West), Shanghai, 200040, China \\ 中国上海市延安西路65号上海国际贵都大饭店办公楼 405 单元 \\ Phone: +86-21-62489820 \\ Fax: +86-21-62489821
}


(C) 2012 The Author(s). Licensee IntechOpen. This is an open access article distributed under the terms of the Creative Commons Attribution 3.0 License, which permits unrestricted use, distribution, and reproduction in any medium, provided the original work is properly cited. 